\title{
Measurement of serum interferon alpha in Egyptian patients with systemic lupus erythematosus and evaluation of its effect on disease activity: a case-control study
}

\author{
A. Fayed ${ }^{1}$, M.M. El Menyawi' ${ }^{2}$ M. Ghanema², O. Shaker ${ }^{3}$, R. Elgohary ${ }^{2}$ \\ ${ }^{1}$ Nephrology unit, Internal Medicine Department, Kasr Alainy School of Medicine, Cairo University, Egypt; \\ ${ }^{2}$ Rheumatology \& Clinical Immunology unit, Internal Medicine Department, Kasr Alainy School of Medicine, \\ Cairo University, Egypt; ${ }^{3}$ Medical Biochemistry and Molecular Biology, Kasr Alainy School of Medicine,
}

Cairo University, Egypt

\section{SUMMARY}

Much evidence highlighted the role of interferon alpha (IFN- $\alpha$ ) in systemic lupus erythematosus (SLE) and suggested its possible role in assessing disease activity. We measured serum IFN- $\alpha$ in Egyptian SLE patients in order to determine a cutoff value that can be used to distinguish patients from healthy controls and explored its clinical value in monitoring disease activity and different aspects of the disease, in particular lupus nephritis. This cross-sectional, case-control study was conducted on 59 SLE patients and 30 healthy controls. Serum IFN- $\alpha$ was measured in all participants using sensitive enzyme-linked immunosorbent assay (ELISA). SLE patients underwent assessment of disease activity using the SLE disease activity index-2000 (SLEDAI-2K) as well as an evaluation of proteinuria, complement $\mathrm{C} 3$ and $\mathrm{C} 4$, and serology. Patients with evidence of renal involvement underwent renal biopsy.

The median serum IFN- $\alpha$ was $81.8 \mathrm{pg} / \mathrm{mL}$ (interquartile range [IQR] 63.4:102.4), which was significantly higher than in healthy controls (median $10.3 \mathrm{pg} / \mathrm{mL}$ [IQR 7.3:11.6]) $(\mathrm{p}<0.001)$. At serum level of $14.7 \mathrm{pg} / \mathrm{mL}$, IFN- $\alpha$ has high sensitivity and specificity to discriminate SLE patients from controls, with high positive and negative predictive values. Serum IFN- $\alpha$ was not associated with markers of disease activity, clinical features and anti-double stranded DNA. Furthermore, it was not associated with markers of renal activity, including proteinuria, $\mathrm{C} 3$ and $\mathrm{C} 4$ complement factors and histopathology renal classes.

Despite elevated levels of serum IFN- $\alpha$ in SLE patients, it is not possible to use it as a biomarker for disease activity.

Key words: Systemic lupus erythematosus; lupus nephritis; interferon alpha (IFN- $\alpha$ ).

Reumatismo, 2020; 72 (3): 145-153

\section{INTRODUCTION}

ystemic lupus erythematosus (SLE) is an autoimmune disease characterized by dysfunctional immune tolerance to nuclear antigens resulting in widespread organ damage (1).

SLE has heterogeneous clinical and laboratory features, which lead to difficulties in diagnosis and makes the assessment of disease activity challenging for clinicians. A significant progress has been made in developing biomarkers for diagnosis and assessment of disease activity. Serum complement factors $\mathrm{C} 3$ and $\mathrm{C} 4$ concentrations, as well as anti-dsDNA titers have been used for decades in the diagnosis and follow up of SLE, in particular in lupus nephritis (2), yet there are still many unmet needs for developing simple and reliable biomarkers that can improve the quality of care for SLE patients (3). Interferon alpha (IFN- $\alpha$ ) is a key molecule in immune regulation and is mainly produced by plasmacytoid dendritic cells, where it stands at the cross-road between innate and adaptive immunity (4).

Much evidence has established increased expression of IFN- $\alpha$-inducible genes and serum IFN- $\alpha$ levels in lupus patients and $\overline{\text { Corresponding author: }}$

Rasmia Elgohary

Cairo University Hospitals, Al-Saray St.

El-Maniel, 11562, Cairo, Egypt

E-mail: rasmiaelgohary@kasralainy.edu.eg 
has highlighted its role in initiating and perpetuating $\operatorname{SLE}(5,6)$. The IFN signatures in SLE were shown to be complex and may not be confined to IFN- $\alpha$. Indeed, also IFN- $\beta$ and IFN- $\gamma$ may contribute to the signature of IFN (7). Therefore, direct assessment of serum IFN- $\alpha$ may be more accurate and specific to monitor disease activity rather than the IFN signature. In this respect, a number of studies have recommended the use of serum IFN- $\alpha$ as a useful biomarker that can assess SLE disease activity $(8,9)$ and identify patients who are at risk of future disease flares (10). However, serum IFN- $\alpha$ has proved to be correlated with ethnicity (9).

The role of serum IFN- $\alpha$ in SLE disease activity was not properly studied in Egyptian populations. Accordingly, in the current study we aimed at measuring serum IFN- $\alpha$ in Egyptian SLE patients using a sensitive enzyme-linked immunosorbent assay (ELISA) in order to identify any possible association between its levels and the markers of disease activity, the presence of anti-double-stranded DNA (dsDNA), and also different clinical aspects, in particular lupus nephritis. We also identified the best cutoff value of serum IFN- $\alpha$ that can discriminate SLE from healthy controls (HC).

\section{PATIENTS AND METHODS}

In this cross-sectional, case-control study, serum IFN- $\alpha$ was measured in 59 SLE patients (males/female: $3 / 56$, with a mean age of $31.7 \pm 9$ years) and 30 age- and sexmatched healthy volunteers (males/female: $2 / 28$, with a mean age of $31.1 \pm 9.9$ years).

SLE patients were recruited consecutively from the rheumatology and clinical immunology outpatient clinic of the Internal Medicine Department at Kasr Alainy Hospital from November 2018 to March 2019. All patients fulfilled the Systemic Lupus International Collaborating Clinics (SLICC) classification criteria for the diagnosis of SLE (11).

Patients with evidence of overlap with other systemic immune diseases were excluded. In addition, subjects with other comorbidities, such as major infection or any malignancy, were excluded, as these conditions may influence IFN- $\alpha$ concentrations. The demographics, clinical characteristics, disease duration, medication history and disease activity were recorded for all patients. The disease activity was assessed using the Systemic Lupus Erythematosus Disease Activity Index 2000 (SLEDAI-2K) score (12). Inactive disease was defined as SLEDAI-2K score $<4$, while active disease was defined as SLEDAI-2K score $\geq 4$ (13). The following laboratory tests were performed for SLE patients: complete blood count $(\mathrm{CBC})$, serum creatinine, urea, lipid profile, erythrocyte sedimentation rate (ESR), C-reactive protein (CRP), 24-h urinary protein, anti-dsDNA and complement $\mathrm{C} 3$ and $\mathrm{C} 4$.

Serum IFN- $\alpha$ was measured according to the manufacturer's instructional protocol using the ELISA assay that was supplied by Bioassay Technology Laboratory, Shanghai, China (Cat. No E0076Hu), which leads to an accurate quantitative detection of very low serum INF- $\alpha$ with sensitivity $2.12 \mathrm{pg} / \mathrm{mL}$.

Renal biopsy was performed in patients with clinical and laboratory evidence of renal involvement as defined based on urine protein excretion $\geq 500 \mathrm{mg} /$ day, cellular casts, unexplained hematuria, or unexplained increases in serum creatinine (14). The class of lupus nephritis was then classified according to the International Society of Nephrology/Renal Pathology Society (ISN/RPS) 2003 classification system (15). All assays were done in blind mode with respect to the clinical data. All participants provided a signed informed consent, and the study was approved by the local ethics committee.

\section{Statistical analysis}

Data were coded and entered using the statistical package SPSS (Statistical Package for the Social Sciences) version 25. The normality of the data was tested using Shapiro-Wilk test. Quantitative data were summarized using mean, standard deviation, median, and inter-quartile range and categorical data were summarized using frequency and percentage. Mann Whitney test 
was used to compare quantitative variables between two groups in non-parametric data (SD $>30 \%$ mean), while Kruskal-Wallis test was used to compare quantitative variables between more than two groups in nonparametric data ( $\mathrm{SD}>30 \%$ mean), then the pairwise comparison test was used to find any statistical difference between each of two groups. For comparing categorical data, the Chi square $\left(\chi^{2}\right)$ test was performed. Correlations between quantitative variables were done using Spearman correlation coefficient. A receiver operator characteristic (ROC) curve was done using the Med-Calc program to determine the best cut-off of serum IFN $\alpha$ that can discriminate SLE patients from healthy controls. $p$ values less than 0.05 were considered as statistically significant, and those less than 0.01 were considered as highly statistically significant.

\section{RESULTS}

The demographics of SLE patients are presented in Table I. The enrolled SLE patients were predominantly females (94\%), their mean age was $31.7 \pm 9$ years, the median disease duration was 48 months with an IQR of 12:96, and the median SLEDAI$2 \mathrm{~K}$ was 5 with IQR of $0: 11$. More than half of the patients $(68 \%)$ had an active disease defined as SLEDAI-2K score $\geq 4$, while an inactive disease was observed in $32 \%$. The enrolled patients reflected the different disease spectrum; lupus nephritis (LN) was the most frequent manifestation found in 51\% followed by arthritis (34\%) and muco-cutaneous manifestations (32\%) (Table I). Regarding the renal histopathology classification of lupus nephritis, $43 \%$ of the patients (13 patients) had class II, 13\% (4 patients) had class III, 33\% (10 patients) had class IV, 3\% (one patient) had class V and $7 \%$ (2 patients) had class II-III.

In SLE patients, the median serum IFN- $\alpha$ was $81.8 \mathrm{pg} / \mathrm{mL}$ with IQR of $63.4: 102.4$, which was significantly higher than that reported in healthy subjects (median $10.3 \mathrm{pg} / \mathrm{ml}$ [IQR 7.3:11.6]) $(\mathrm{p}<0.001)$ (Figure 1A). At a serum level of $14.7 \mathrm{pg} / \mathrm{mL}$, IFN- $\alpha$ has a sensitivity and specificity of $100 \%$ to dis- criminate SLE patients from controls, with high positive and negative predictive values (Figure 1B, Table II).

The IFN- $\alpha$ levels showed no correlations with patients' age and disease duration (Table III). Also, IFN- $\alpha$ levels were not associated with the dose of hydroxychloroquine and prednisone treatment (Table III). The IFN- $\alpha$ levels did not differ between patients receiving prednisone (mean $=84.7 \mathrm{pg} / \mathrm{mL}$ $[\mathrm{IQR}=63.1: 117.2])$ versus those who were not on prednisone (mean $=80.4 \mathrm{pg} / \mathrm{mL}$ $[\mathrm{IQR}=64.8: 91.9]$ ) ( $\mathrm{p}$ value 0.581 ), and the same was found for hydroxychloroquine ( $\mathrm{p}$ value 0.595 ) (data not displayed).

Serum IFN- $\alpha$ was not correlated with dis-

Table I - Demographics, clinical, laboratory and therapeutic characteristics of SLE patients.

\begin{tabular}{|c|c|c|}
\hline \multirow{2}{*}{ Gender N (\%) } & Male & $3(5.1)$ \\
\hline & Female & $56(94.9)$ \\
\hline \multicolumn{2}{|l|}{ Age (mean \pm SD) } & $31.7 \pm 9$ \\
\hline \multicolumn{2}{|l|}{ BMI (mean \pm SD) } & $27.6 \pm 7.1$ \\
\hline \multicolumn{2}{|c|}{ Disease duration in months [median (IQR)] } & $48(12: 96)$ \\
\hline \multirow{3}{*}{ SLEDAI-2K score } & Total score [median (IQR)] & $5(0: 11)$ \\
\hline & Number of active SLE (\%) & $40(68 \%)$ \\
\hline & Number of inactive SLE (\%) & $19(32 \%)$ \\
\hline \multirow{7}{*}{$\begin{array}{l}\text { Distribution of SLE } \\
\text { features } N(\%)\end{array}$} & Lupus nephritis & $30(51)$ \\
\hline & Arthritis & $20(34)$ \\
\hline & Muco-cutaneous & $19(32)$ \\
\hline & Neuro-psychiatric & $7(12)$ \\
\hline & Hematological & 7 (12) \\
\hline & Fever & $6(10)$ \\
\hline & Serositis & $4(7)$ \\
\hline \multicolumn{2}{|c|}{ 24-h urinary proteins (g/day) [median (IQR)] } & $0.3(0.11: 1.1)$ \\
\hline \multicolumn{2}{|c|}{ Serum creatinine (mg/dL) [median (IQR)] } & $0.7(0.6: 0.89)$ \\
\hline \multicolumn{2}{|c|}{ Hemoglobin (g/dl) [median (IQR)] } & $11(10: 12)$ \\
\hline \multirow{3}{*}{ Serology N (\%) } & ANA & $59(100)$ \\
\hline & Anti-ds DNA & $40(68)$ \\
\hline & Low complement C3/C4 levels & $19(32)$ \\
\hline \multirow{2}{*}{ Prednisolone } & $\mathrm{N}(\%)$ & $23(39)$ \\
\hline & Dose, mean $\pm S D$ & $24.8 \pm 17.2 \mathrm{mg} / \mathrm{dL}$ \\
\hline \multirow{2}{*}{ Hydroxychloroquine } & $\mathrm{N}(\%)$ & $44(75)$ \\
\hline & Dose, mean \pm SD & $260.87 \pm 94.09 \mathrm{mg} / \mathrm{dL}$ \\
\hline
\end{tabular}

$\mathrm{N}$, number, SD, standard deviation; IQR, interquartile range; SLEDAI-2K, SLE disease activity index-2000; ANA, anti-nuclear antibodies; Anti-ds DNA, antidouble stranded DNA. 


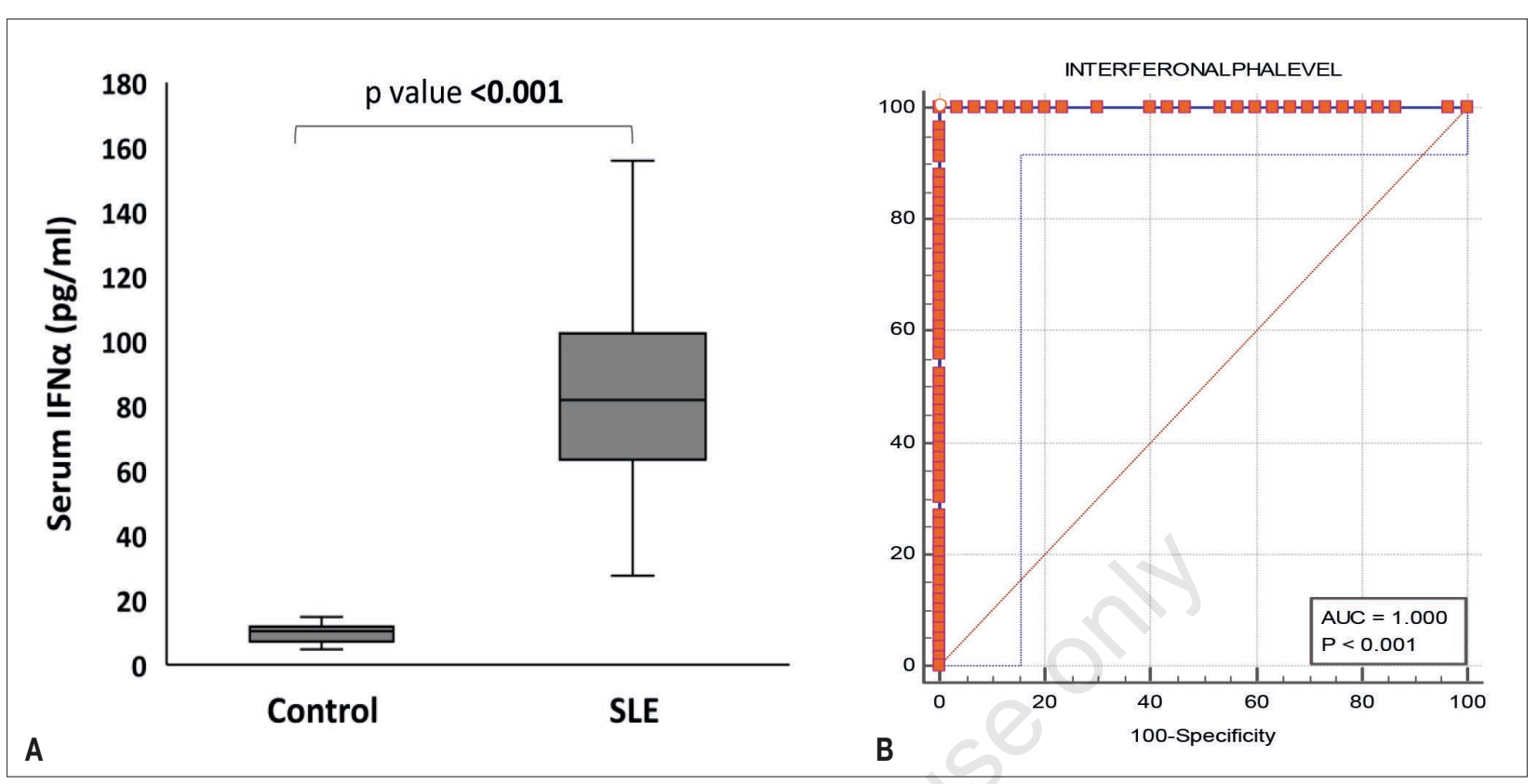

Figure 1 - (A) The serum concentrations of IFN- $\alpha$ in SLE patients and healthy controls (B) ROC curve analysis: showed the diagnostic performance of IFN- $\alpha$ for discriminating SLE patients from healthy controls.

Table II - Sensitivity and specificity of serum IFN- $\alpha$ in discriminating SLE patients from healthy controls.

\begin{tabular}{|c|c|c|c|c|c|c|c|}
\hline Cut off value $(\mathrm{pg} / \mathrm{mL})$ & AUC & 95\% Confidence interval & P value & Sensitivity & Specificity & PPV & NPV \\
\hline$>14.1$ & 1.000 & 0.959 to 1.000 & $<0.0001$ & 100 & 96.67 & 98.3 & 100 \\
\hline$>14.7$ & 1.000 & 0.959 to 1.000 & $<0.0001$ & 100 & 100 & 100 & 100 \\
\hline$>27.5$ & 1.000 & 0.959 to 1.000 & $<0.0001$ & 96.61 & 100 & 100 & 93.7 \\
\hline
\end{tabular}

AUC, area under the curve; PPV, positive predictive value; NPV, negative predictive value.

Table III - Correlations of serum IFN- $\alpha$ with different variables in SLE patients.

\begin{tabular}{|l|c|c|}
\hline \multirow{2}{*}{} & \multicolumn{2}{|c|}{ Interferon alpha level } \\
\cline { 2 - 3 } & $\mathbf{r}$ & $\mathrm{p}$ value \\
\hline Age & 0.015 & 0.908 \\
\hline Hemoglobin & -0.2 & 0.128 \\
\hline WBCs count & -0.003 & 0.982 \\
\hline Platelet count & -0.193 & 0.143 \\
\hline ESR (mm/hour) & -0.028 & 0.834 \\
\hline CRP (mg/dL) & -0.136 & 0.305 \\
\hline 24 hours urinary protein & 0.0775 & 0.559 \\
\hline Prednisone dose (mg/day) & 0.075 & 0.735 \\
\hline Hydroxychloroquine dose (mg/day) & 0.242 & 0.265 \\
\hline Duration of SLE (months) & -0.165 & 0.211 \\
\hline SLEDAl-2K score & -0.222 & 0.09 \\
\hline
\end{tabular}

r, Spearman's correlation coefficient; WBCs, white blood cells; SLEDAI-2K, SLE Disease Activity Index-2000; ESR, erythrocyte sedimentation rate; CRP, C-reactive protein. ease activity as assessed by SLEDAI-2K score (Table III) and the serum IFN- $\alpha$ did not differ between active and inactive SLE groups. However, inactive SLE patients still had significantly higher concentrations of IFN- $\alpha$ compared to healthy controls $(\mathrm{p}<0.001)$ (Figure 2A). Moreover, serum IFN- $\alpha$ did not differ between patients with low complement, as an indicator of disease activity, and those with normal complement (Figure 2B).

As SLEDAI-2K score reflects a heterogeneous disease spectrum, we studied the INF- $\alpha$ levels in patients with different clinical features. Patients with lupus nephritis had higher IFN- $\alpha$ levels (median $84 \mathrm{pg} /$ $\mathrm{mL}$ [IQR 67.5:106.9]) than those without renal manifestations (median $77.9 \mathrm{pg} / \mathrm{mL}$ [IQR 55.2:94.8]). However, no significant difference was found (Figure 2C); the con- 


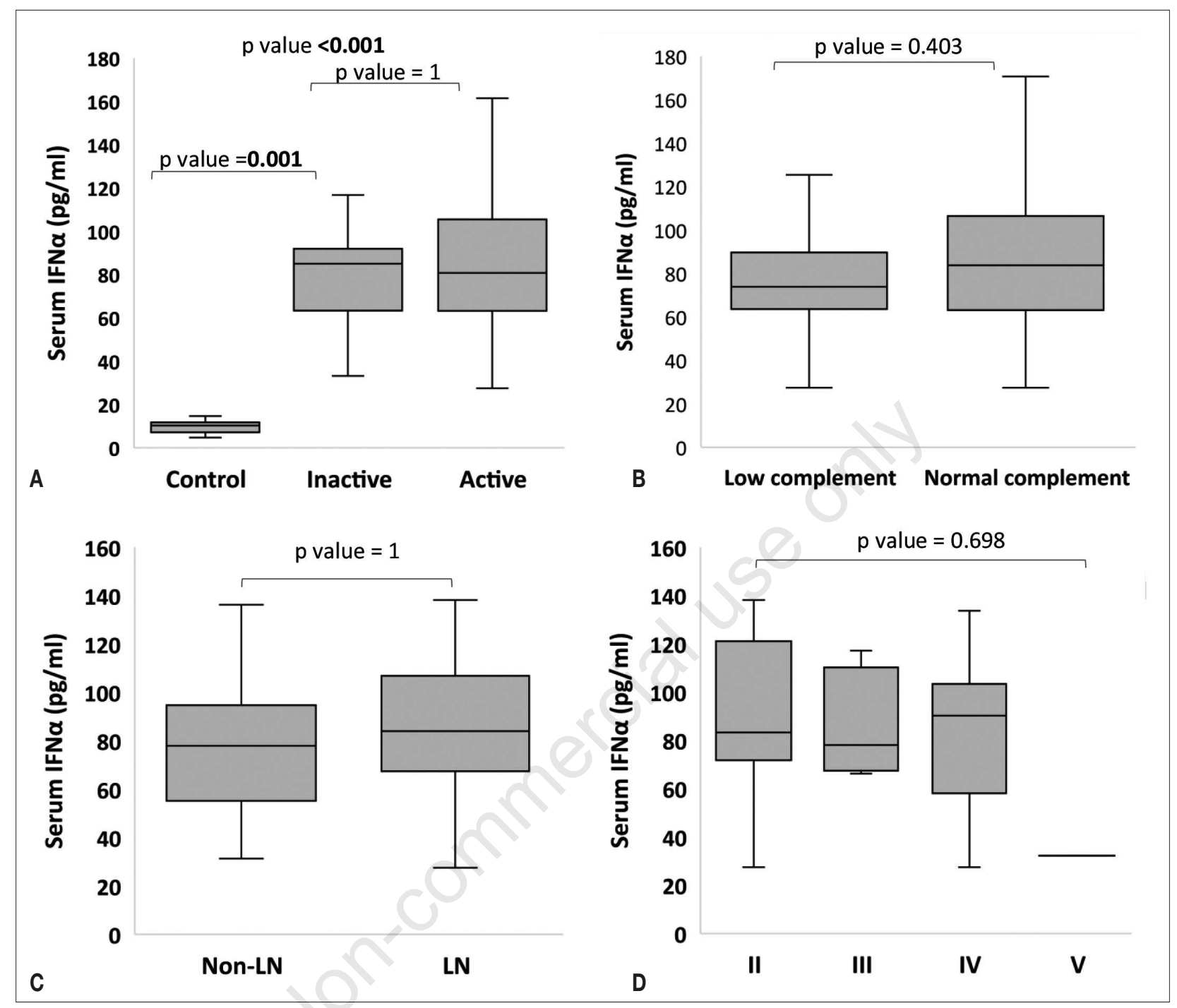

Figure 2 - (A) The serum concentrations of IFN- $\alpha$ in healthy control, inactive and active SLE patients. (B) The concentration of serum IFN- $\alpha$ in lupus patients with low complement and those with normal complement. (C) The concentration of serum IFN- $\alpha$ in lupus nephritis and non-lupus nephritis. (D) The concentration of serum IFN- $\alpha$ in different classes of renal biopsies obtained from SLE patients with lupus nephritis.

centrations were also not significantly different among different LN classes (Figure 2D). In addition, no association between IFN- $\alpha$ levels and proteinuria was observed (Table III). Serum IFN- $\alpha$ also did not differ according to different clinical features, including arthritis, serositis, muco-cutaneous, hematological and neuro-psychiatric manifestations (Figure 3A-B).

Finally, both patients with or without positive anti-ds DNA antibodies had high serum IFN- $\alpha$ levels with no significant differences (Figure 3C). Furthermore IFN- $\alpha$ levels in patients with both positive anti-ds DNA and low complement (median $83.1 \mathrm{pg} / \mathrm{mL}$ [IQR 63.5:104.45]) were higher compared to other patients (median $69.3 \mathrm{pg} / \mathrm{mL}$ [IQR 34.3:85.8]), but with no significant statistical difference ( $p$ value 0.231) (data not shown).

\section{DISCUSSION}

In the current study we found higher levels of serum IFN- $\alpha$ in Egyptian SLE patients than in healthy subjects. This finding has 


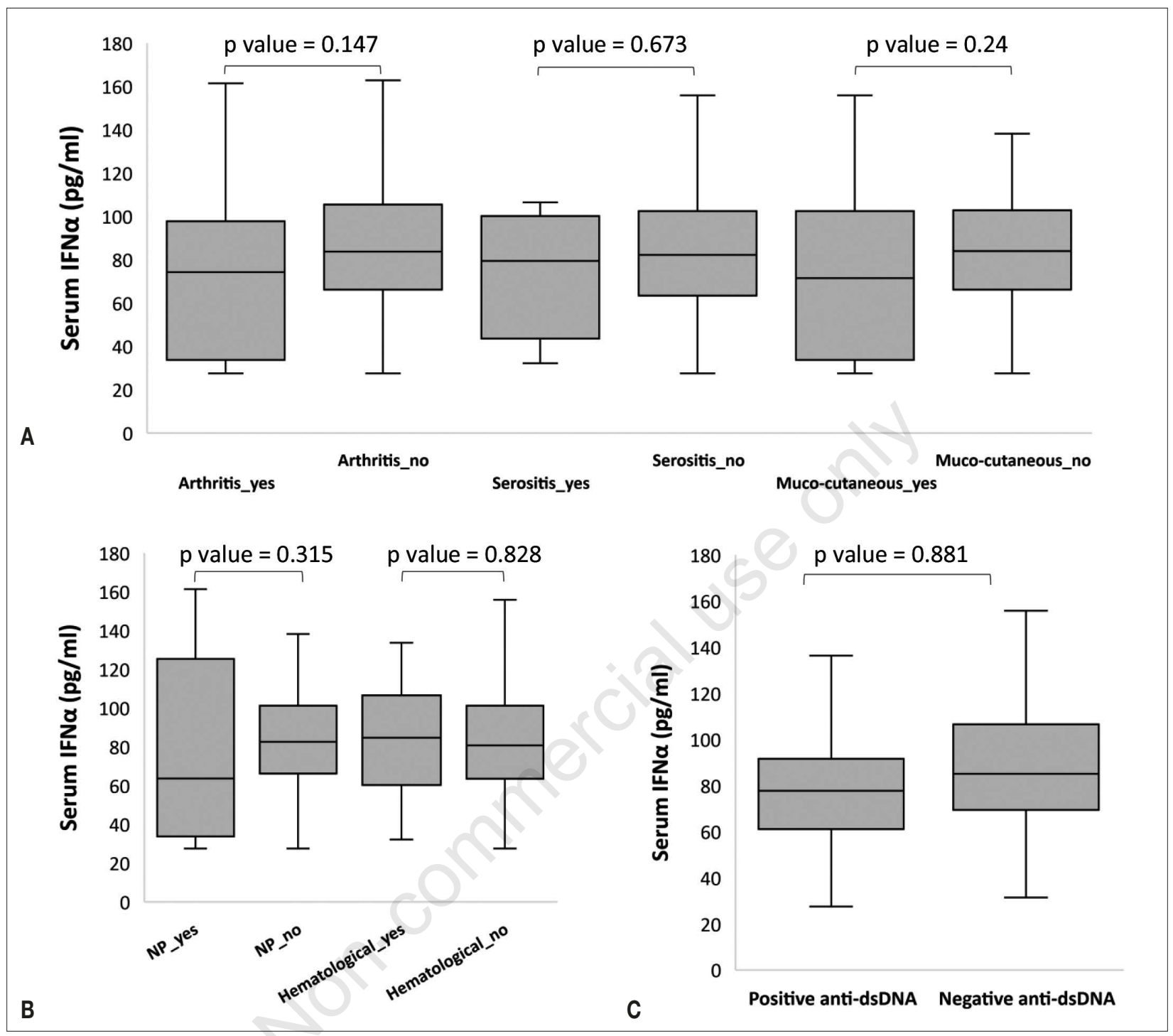

Figure 3 - (A \& B) Comparison of serum IFN- $\alpha$ in different disease manifestations. (C) comparison of serum IFN- $\alpha$ in patients with positive anti-dsDNA and those with negative antibodies.

already been reported in previous studies $(8,16,17)$ and emphasized a role of IFN- $\alpha$ in SLE patients.

At a serum level of $14.7 \mathrm{pg} / \mathrm{ml}$, IFN- $\alpha$ has a high sensitivity and specificity to discriminate SLE patients from healthy controls, with high positive and negative predictive values. Despite its importance, the standardization of a cutoff value may be difficult, as the commercially available assays have different sensitivities.

The increased levels of IFN- $\alpha$ in our patients were not associated with disease activity as assessed by SLEDAI-2K score.
However, this should be interpreted with caution, because the sample size is relatively limited and the same SLEDAI-2K might reflect a heterogenous spectrum of disease involvement. We also found that patients with inactive disease had similar serum IFN- $\alpha$ levels compared to patients with active disease, but when compared to controls, they had significantly higher levels of IFN- $\alpha$. Moreover, no significant difference was found between patients with or without a low complement, as a marker of disease activity.

Also, serum IFN- $\alpha$ levels were not associ- 
ated with proteinuria and did not differ in patients with lupus nephritis compared to those without renal involvement. In addition, serum IFN- $\alpha$ was similar in the patient subgroup with renal involvement in the renal nephritis class. These data raised a concern about the significance of the crosssectional evaluation of serum IFN- $\alpha$ in the assessment of disease activity in Egyptian SLE patients.

Some gene expression studies have shown that IFN- $\alpha$ signature in SLE patients is associated with disease activity, when assessed cross sectionally $(5,18,19)$. However, IFN signatures in SLE are complex and may be not restricted to IFN- $\alpha$, but also involve IFN- $\beta$ and IFN- $\gamma$ (7).

Results concerning the clinical meaning of serum IFN- $\alpha$ are inconsistent across the available literature, as some studies have found a cross-sectional relationship with disease activity $(8,9,17)$, whereas other studies have not observed a possible correlation (20). Interestingly, a recent longitudinal study found that a significant proportion of patients, despite being in remission, have high serum IFN- $\alpha$ levels that were found to predict independently the risk of subsequent SLE flares. Also the patients in clinical remission with serological activity presented more frequently elevated serum levels of IFN- $\alpha$ than patients in complete clinical and serological remission (10).

We found no associations between the IFN- $\alpha$ levels and the current doses of prednisone and/or hydroxychloroquine and no significant difference in IFN- $\alpha$ levels among patients who were taking these drugs compared to those who did not. Similarly to our findings, Jolly et al. found no statistical difference in interferon activity, when comparing the different medications that patients were on (including prednisone, other immunosuppressive drugs, hydroxychloroquine, or non-steroidal antiinflammatory agents) (20). However, the use of large doses of methylprednisolone may affect the IFN- $\alpha$, as was demonstrated by another study that showed a dramatic decrease in the expression of IFN-inducible genes in lupus patients who received pulse glucocorticoid therapy (18).
Our study found that both patients with or without positive anti-ds DNA antibodies had high serum IFN- $\alpha$ levels with no significant difference. We assumed that antidsDNA antibodies alone are not enough for activation of IFN- $\alpha$ pathway and other disease-specific factors may be important. A similar assumption was made by Niewold et al., who found high levels of type I IFN in sera of maternal lupus, regardless of the presence of anti-SSA/Ro antibodies (21). In addition, one study found elevated IFN- $\alpha$ levels in healthy relatives of SLE patients in whom autoantibodies against dsDNA and RNA-binding proteins (RBP) were very uncommon (16).

This was not in agreement with an experimental study showing that sera containing immune complexes containing nucleic acid released by necrotic or late apoptotic cells can activate plasmacytoid dendritic cells and promote type I IFN production which in turn enhances toll like receptor-7 (TLR7) signaling, therefore, forming a positive feedback loop, suggesting a strong association between SLE-associated autoantibodies and serum IFN- $\alpha$ (22). Also, our findings were not consistent with other clinical studies which found that the presence of antibodies specific for dsDNA (9, 16, 23), RNP and SSA/Ro were associated with the levels of serum IFN- $\alpha$ (10).

We found no association between serum IFN- $\alpha$ and the different disease manifestations. This is partially consistent with other studies reporting that IFN- $\alpha$ was associated with skin disease $(8,9)$, but not with other clinical manifestations including neurological, and renal diseases (9) as well as arthritis, and Raynaud's phenomenon $(8,9)$.

Based on our findings we assume that IFN- $\alpha$ overproduction in our lupus patients may be related to other factors rather than disease activity and dsDNA autoantibodies. Both genetic and environmental factors may be important and should be investigated further. One Egyptian study showed high serum IFN- $\alpha$ in SLE patients and their first-degree relatives compared to healthy unrelated controls (23). Another study found a clustering of high serum IFN- $\alpha$ in lupus families com- 
pared to healthy unrelated individuals. The authors observed strong familial correlations in serum IFN- $\alpha$, regardless of disease status, and SLE probands in the same family tended to have similar levels of serum IFN- $\alpha$, and accordingly they suggested that high serum IFN- $\alpha$ in SLE patients may be explained by genetic susceptibility (16).

\section{Limitations of our study}

The present study has a few of limitations. The sample size of our cohort was relatively small, therefore our findings may not be extensively generalized. Another limitation is the lack of long-term follow-up, which might show variations in terms of serum IFN- $\alpha$ levels according to different circumstances. Finally, the study did not include disease controls with systemic autoimmune diseases other than SLE, which would be important to determine the optimal cut-off for IFN- $\alpha$ in SLE patients compared to other autoimmune diseases.

\section{CONCLUSIONS}

In conclusion, serum IFN- $\alpha$ was elevated in Egyptian SLE patients compared to HC. However, it was not associated with disease activity, any of the clinical features and anti-dsDNA antibodies. In addition, serum IFN- $\alpha$ was not associated with any indicators of renal activity, including proteinuria, serum $\mathrm{C} 3$ and $\mathrm{C} 4$ complement and histopathology renal classes. These findings challenged the role of serum IFN- $\alpha$ as a reliable biomarker in Egyptian SLE patients. Further studies with a larger sample and longitudinal design are recommended to confirm these results.

\section{Authorship}

All authors have contributed significantly and equally in the design of this work, data acquisition, analysis and interpretation. In addition to writing and revising this manuscript, all authors approved the final version before submission.

\section{Conflicts of Interest}

The authors declared to have no conflicts of interest. This research did not receive any specific grant from any funding agency in the public, commercial or not-for-profit sector.

\section{Ethical Committee Approval}

The Institutional Review Board at Faculty of Medicine, Cairo University, approved this work.

\section{Human and Animal Rights}

All procedures performed in this study involving human participants were in accordance with the ethical standards of the institutional and/or national research committee and with the 1964 Helsinki Declaration and its later amendments or comparable ethical standards.

\section{Informed consent}

Informed consent was obtained from all individual participants included in the study.

\section{REFERENCES}

1. Crow MK. Type I interferon in the pathogenesis of lupus systemic lupus erythematosus. J Immunol. 2014; 192: 5459-68.

2. Liu CC, Kao AH, Manzi S, Ahearn JM. Biomarkers in systemic lupus erythematosus: Challenges and prospects for the future. Ther Adv Musculoskelet Dis. 2013; 5: 210-33.

3. Zeng J, Wu H, Zhao M, Lu Q. Novel biomarkers for systemic lupus erythematosus. Biomark Med. 2017; 11: 677-86.

4. Meyer O. Interferon-alpha as a treatment target in systemic lupus erythematosus. Jt Bone Spine 2012; 79: 113-6.

5. Feng X, Wu H, Grossman JM, et al. Association of increased interferon-inducible gene expression with disease activity and lupus nephritis in patients with systemic lupus erythematosus. Arthritis Rheum. 2006; 54: 2951-62.

6. Petri M, Singh S, Tesfasyone H, et al. Longitudinal expression of type I interferon responsive genes in systemic lupus erythematosus. Lupus 2009; 18: 980-9.

7. Chiche L, Jourde-Chiche N, Whalen E, et al. Modular transcriptional repertoire analyses of adults with systemic lupus erythematosus reveal distinct type I and type II interferon signatures. Arthritis Rheumatol. 2014; 66: 158395.

8. Ytterberg SR, Schnitzer TJ. Serum interferon levels in patients with systemic lupus erythematosus. Arthritis Rheum. 1982; 25: 401-6.

9. Dall'Era MC, Cardarelli PM, Preston BT, et al. Type I interferon correlates with serologi- 
cal and clinical manifestations of SLE. Ann Rheum Dis. 2005; 64: 1692-7.

10. Mathian A, Mouries-Martin S, Dorgham K, et al. Ultrasensitive serum interferon- $\alpha$ quantification during SLE remission identifies patients at risk for relapse. Ann Rheum Dis. 2019; 78: 1669-76.

11. Isenberg D, Wallace DJ, Nived O, et al. Derivation and validation of systemic lupus international collaborating clinics classification criteria for systemic lupus erythematosus. Arthritis Rheum. 2013; 64: 2677-86.

12. Gladman DD, Ibañez D, Urowitz MB. Systemic lupus erythematosus disease activity index. J Rheumatol. 2002; 29: 288-91.

13. Yee CS, Farewell VT, Isenberg DA, et al. The use of systemic lupus erythematosus disease activity index-2000 to define active disease and minimal clinically meaningful change based on data from a large cohort of systemic lupus erythematosus patients. Rheumatology 2011; 50: 982-8.

14. Bertsias GK, Tektonidou M, Amoura Z, et al. Joint European League Against Rheumatism and European Renal Association-European Dialysis and Transplant Association (EULAR/ ERA-EDTA) recommendations for the management of adult and paediatric lupus nephritis. Ann Rheum Dis. 2012; 71: 1771-82.

15. Weening JJ, D'Agati VD, Schwartz MM, et al. The classification of glomerulonephritis in systemic lupus erythematosus revisited. J Am Soc Nephrol. 2004; 15: 241-50.

16. Niewold TB, Hua J, Lehman TJA, et al. High serum IFN- $\alpha$ activity is a heritable risk factor for systemic lupus erythematosus. Genes Immun. 2007; 8: 492-502.
17. Al Tahhan M, El-Toukhy M, Salem E. Serum nerve growth factor, interleukin-13 and tumor necrosis factor- $\alpha$ in patients with systemic lupus erythematosus. Bull Egypt Soc Physiol Sci. 2009; 29: 151-64.

18. Kirou KA, Lee C, George S, et al. Activation of the interferon- $\alpha$ pathway identifies a subgroup of systemic lupus erythematosus patients with distinct serologic features and active disease. Arthritis Rheum. 2005; 52: 1491-503.

19. Fu Q, Chen X, Cui H, et al. Association of elevated transcript levels of interferoninducible chemokines with disease activity and organ damage in systemic lupus erythematosus patients. Arthritis Res Ther. 2008; 10: 1-10.

20. Jolly M, Francis S, Aggarwal R, et al. Serum free light chains, interferon-alpha, and interleukins in systemic lupus erythematosus. Lupus 2014; 23: 881-8.

21. Niewold TB, Rivera TL, Buyon JP, Crow MK. Serum type I interferon activity is dependent on maternal diagnosis in anti-SSA/Ro-positive mothers of children with neonatal lupus. Arthritis Rheum. 2008; 58: 541-6.

22. Lövgren T, Eloranta ML, Båve U, et al. Induction of interferon- $\alpha$ production in plasmacytoid dendritic cells by immune complexes containing nucleic acid released by necrotic or late apoptotic cells and lupus IgG. Arthritis Rheum. 2004; 50: 1861-72.

23. Shahin D, El-Refaey AM, El-Hawary AK, et al. Serum interferon-alpha level in first degree relatives of systemic lupus erythematosus patients: Correlation with autoantibodies titers. Egypt J Med Hum Genet. 2011; 12: 139-46. 